Cad.Est.Ling., Campinas, 47(1) e (2):19-27, 2005

\title{
A CRIANÇA E A PROSÓDIA: UMA RETROSPECTIVA E NOVOS DESENVOLVIMENTOS
}

\author{
ESTER MIRIAN SCARPA \\ (IEL, Universidade Estadual de Campinas)
}

\begin{abstract}
This is a retrospective of my former work on the acquisition of prosody and specifically the role of the double face of prosody in acquisition is revisited. Also revisited are the notions of discontinuity and continuity by Jakobson and their insuing misinterpretations in the literature in further work on aphasia and phonology acquisition. Finally an approximation of the concepts of continuity/discontinuity and double face of prosody with "double vocation" by Didier-Weill is proposed.
\end{abstract}

Começo do princípio. Quando Cláudia aqui chegou, em princípios de 1976, sua inquietude intelectual causou impacto no jovem Departamento de Lingüística e deixou marcas duradouras nos rumos da pesquisa do Departamento, posteriormente transformado em Instituto de Estudos da Linguagem, com a incorporação do recém-fundado Departamento de Teoria Literária. Do testemunho de sua inquietude intelectual lembro-me de um pequeno cartaz afixado na parede de sua sala, talvez trazido de Edimburgo, que dizia mais ou menos:

"Change is here to stay".

A mudança - na aquisição e nos novos desafios teóricos - aliada à coerência e à seriedade desde sempre têm marcado sua trajetória e o trabalho dos que foram por ela formados ou afetados. Novos desafios e coerência: esta é uma de suas heranças. E não é pouco.

Nesta breve retrospectiva, gostaria de tentar mostrar como o diálogo com o trabalho de Cláudia tem subjazido minhas reflexões sobre a aquisição da linguagem e que, mesmo tomando rumos próprios, meu trabalho encontra no dela um contraponto frutífero e instigante. A ele - seu trabalho - presto tributo.

Vamos à retrospectiva.

No começo do ano letivo de 1976, Cláudia Lemos reunia um pequeno grupo (Maria Cecília Perroni, Rosa Attié Figueira, Maria Fausta Pereira de Castro e eu mesma) interessado em aquisição da linguagem e, no segundo semestre, oficializou-se o Projeto de Aquisição do IEL. Cláudia aliava suas fortes preocupações teórico-metodológicas ao desejo de 
SCARPA - A criança e a prosódia: uma retrospectiva

formação de um grupo de pesquisadores que levassem à frente os desafios que a pesquisa em Aquisição da Linguagem pudesse propiciar. Passou, então, à elaboração de um projeto temático e à organização de um grupo que fosse também responsável pela coleta e transcrição de dados naturalísticos aquisicionais do português brasileiro, pioneiro no Brasil, tanto com respeito à natureza de um projeto temático, quanto com relação à postura investigativa nele impressa. O título original do Projeto, auto-explicativo das preocupações teóricas do momento, "Relações entre o desenvolvimento cognitivo e desenvolvimento pré-lingüístico e lingüístico em crianças brasileiras", foi imediatamente superado. A fala da criança desde logo foi a empiria que questionava as posições teóricas do pesquisador, nunca o conjunto de dados a serviço de teorias lingüísticas e psicológicas. Assim, o diálogo com a teoria piagetiana e as gramáticas funcionalistas, consideradas na época como possíveis alternativas não-modularistas ao inatismo chomskiano, logo deram lugar à mudança dos rumos teóricos e metodológicos do projeto, que se posicionaram em favor do que se chamou na época de sócio-interacionismo, elegendo o diálogo e a interação dialógica como fatores tanto operacionais quanto constitutivos da aquisição da linguagem. Houve, desde o início, a recusa à consideração de categorias cognitivas ou comunicativas como apriorísticas, como eventual base para posterior mapeamento lingüístico, tanto quanto se questionava a préformação inata de base lingüística.

Dentro do projeto, numa perspectiva dialógica, meu primeiro interesse, em texto de 1976, foi estudar as manifestações (proto-) aspectuais, marcações vocais ou verbais de fases do evento, de cunho prosódico em situações de interação e interlocução. Consoante à visão de desenvolvimento lingüístico adotada na época, os elementos prosódicos, rica fonte de expressão da produção, pela criança, da holófrase (enunciados cristalizados de uma palavra), preparavam o caminho da marcação léxico-gramatical posterior das categorias de tempo e aspecto.

Obviamente a visão de conhecimento gramatical precocemente marcado não se sustentou por muito tempo, mas me fez aprofundar o interesse nos elementos prosódicos na fala da criança enquanto tais e não apenas como instrumento de veiculação ou atribuição de significados morfossintáticos. Abandonei rapidamente a ligação entre voz e categoria gramatical para estudar a aquisição da entonação, de um ponto de vista dialógico, interacional, segundo o qual a fala da criança, na construção conjunta com o adulto e objetos do mundo, reflete contornos presentes na fala do adulto dirigida a elas, recortados e segmentados em situações dialógicas. Tais desenvolvimentos também são compatíveis com a perspectiva de que a criança, da posição de interpretada, passa à de interpretante, transformando o discurso do outro em discurso próprio. Assim, os erros, migrações e extensões de contornos de altura e outras marcações prosódicas, como a duração, eram vistos como recontextualizações, reinterpretações e reorganizações do sistema entonacional, à luz de outras interações dialógicas.

O próximo passo de minha reflexão volta-se para o fato de que é com a materialidade fônica que a criança se depara na aquisição da língua materna. A indagação correlacionada a ela é: o que há nesta materialidade, instanciada na fala do outro, que a afeta tão grandemente e a encaminha para a entrada na língua? Ou, nas palavras de Didier-Weill (1999): "o som que, como um ímã, atrai o sentido". 
Cadernos de Estudos Lingüísticos 47(1) e (2) - Jan./Dez. 2005

O fato que me saltava aos olhos desde os trabalhos realizados a partir de minha tese de doutorado (Gebara, 1984; Scarpa, 1985a e b) - a rigor, já insinuado na própria tese -é que a prosódia tem dupla face na aquisição. É a via privilegiada de engajamento da criança no diálogo e, ao mesmo tempo, é o veículo primeiro da organização das formas lingüísticas, sobretudo através dos sistemas de ritmo e entonação. A face do caminho privilegiado da chamada da criança ao diálogo que desenvolvi em trabalhos que trataram da prosódia e processos dialógicos (Scarpa, 1985b e 1990), é aquela que se caracteriza como melódica/ entonacional por excelência. A prosódia estabeleceria, pensava eu, a ponte inicial, ligando som e sentido, através da organização formal da fala e o potencial dos efeitos significativos criados pela instanciação da língua nos diálogos. Inscrever-se-iam na materialidade do som, com o qual a criança se depara, tanto a organização do som em estruturas fonológicoprosódicas da língua materna quanto os efeitos de sentido, sejam de cunho textual, sejam discursivos/enunciativos, trazidos de volta pelo próprio movimento dialógico presente na mesma materialidade.

O desenvolvimento seguinte do meu trabalho deu-se em duas frentes, utilizando o instrumental das fonologias não-lineares:

$1^{\mathrm{a})}$ A prosódia como lugar privilegiado da interface entre componentes (não no seu sentido unidirecional, isto é, da sintaxe à fonologia), o que prevê a entrada na língua simultaneamente por vários caminhos e que impede a separação ou a ordenação de componentes. Neste sentido, estudando os sons preenchedores na fala da criança, recuso uma visão estrita de bootstrapping prosódico à sintaxe, segundo a qual o conhecimento prévio gramatical ou sintático seria projetado nos dados através de sílabas guardadoras de lugares prosódicos (Scarpa, 1995; 1999).

$2^{a}$ ) Através de trabalhos sobre os mesmos sons preenchedores e reflexões acerca da aquisição do sândi externo vocálico do português brasileiro, reúno evidências em favor da robustez do acento nuclear na fala dos sujeitos. Tenho chamado este fenômeno, metaforicamente, de "trajetória de cima para baixo" na aquisição da prosódia. Aquela que começa gestalticamente com a entonação, nos domínios prosódicos ditos superiores, isto é, aqueles responsáveis pelo contorno de altura, contra uma visão de complexidade cumulativa sintagmática, muito comum na literatura de Aquisição da Fonologia, que prevê uma complicação que vai da sílaba ao pé métrico, deste à palavra, desta à frase, mesmo que - ou por causa disto mesmo - tome a palavra como unidade básica de análise (Scarpa, 1997; 1999). Uma hipótese alternativa propõe que se separe complexidade sintagmática e hierarquia prosódica e que a criança empreende um trabalho "de cima para baixo" com a organização prosódica, em interação constante com os outros componentes lingüísticos. Parece que o acento nuclear, de cunho entonacional, é o ponto de referência pelo qual a criança é atraída para a linguagem e vislumbra nela um princípio de estruturação.

Antes disso, nos primeiros meses de vida, as modulações da voz da mãe (basicamente movimentos de altura e qualidades várias de voz) mostram-se uma porta ótima de entrada do infante na língua. Cavalcante (1999) mostra as mudanças de posição do infante com relação às modulações de voz da mãe, bem como as mudanças de posição do próprio infante.

A robustez do acento nuclear, que é a proeminência melódico-acentual própria dos domínios prosódicos superiores, se faz ver já desde os primeiros sistemas entonacionais da 
SCARPA - A criança e a prosódia: uma retrospectiva

criança no segundo ano de vida. Evoca exatamente o espaço simbólico ocupado pelos recortes da voz da mãe ou das modulações da mãe que pontuam a voz da criança. Em retrospectiva, vejo que a voz que atrai o infante vai se recompor de outra maneira, dentro dos sistemas de ritmo e entonação do português, quando a criança produz as primeiras "palavras" semelhantes ao léxico de sua comunidade.

Nos últimos anos, a reflexão sobre a fala afásica me traz de volta à aquisição, nos dois lados opostos das franjas do insólito e da normalidade, com a (re)leitura de Jakobson. Mais uma vez, o contraponto com os estudos sobre a relação do sujeito com a língua empreendidos por de Lemos (notadamente, 1992; 1999; 2002) subjazem meus caminhos, assim como influenciaram a geração dos interacionistas na busca da releitura da obra de Saussure e dos grandes estruturalistas (ver os trabalhos deste volume).

\section{Jakobson: continuidade, descontinuidade.}

No clássico artigo "Child Language, Aphasia and Phonological Universals", Jakobson (1941 [1968]) faz afirmações sobre a aquisição da fonologia (também estendida à gramática) que constituíram o que foi chamado, a posteriori, de hipótese da descontinuidade, da identidade ou ainda da regressão, esta quando se trata de afasia ou "dissolução lingüística", nos dizeres do próprio autor.

Como argumentação inicial, Jakobson invoca a dualidade da fala da criança com relação à do adulto: ao mesmo tempo em que é a mesma ("força unificadora"), ela é diferente ("espírito separatista").

O fenômeno da descontinuidade trata da ruptura estrutural ou da reorganização distintiva entre as emissões do balbucio e o sistema fonológico da língua materna, este adquirido no começo da produção das palavras interpretáveis como semelhantes às do adulto. Apesar de que Jakobson traça uma relação cronológica ou desenvolvimentista entre balbucio e sistema propriamente fonológico da criança, creio que seu postulado sobre a descontinuidade deva ser visto mais com o sentido de natureza lingüística diversa entre os sons produzidos no balbucio e os do sistema fonológico da língua materna.

Deve ser dito que o termo "descontinuidade" foi cunhado na área a partir de observações depreciativas posteriores à teoria de Jakobson e é fruto, o termo, de visões que advogam tanto fortes motivações empíricas, fonéticas, para o fato fônico, como também por teorias perceptualistas sobre o que a criança "adquire" no primeiro ano de vida. Mas, como veremos, é um termo que nos convém, sem julgamento de valor.

No balbucio, segundo ele, a criança realiza uma impressionante quantidade e diversidade de produções fônicas. É capaz de "acumular articulações" que não são encontradas numa só língua ou mesmo num grupo de línguas - consoantes de qualquer ponto de articulação, consoantes palatalizadas ou arredondadas, africadas, cliques, vogais complexas - percorrendo potencialmente todo o espectro vocálico e consonântico. O balbucio é, segundo J. (emprestando a metáfora de Preyer) um "tongue delirium", biologicamente orientado. 
Cadernos de Estudos Lingüísticos 47(1) e (2) - Jan./Dez. 2005

Esta faceta, cujo atributo de "delírio da língua" o próprio Jakobson corrobora (a este respeito, ver brilhante exposição em Lier-de Vitto, 1998), vai apresentar uma contraparte descontínua com as primeiras palavras produzidas. A criança, segundo Jakobson, perde, então, a habilidade de produzir toda a gama de sons do balbucio. Os sons - ou melhor dizendo, o valor distintivo dos sons - que não estão presentes na língua de sua comunidade, aqueles que não são simbolizados no sistema fonológico de sua língua, rapidamente desaparecem. Mas não só: muitos sons que são comuns ao balbucio e à língua da comunidade também ficam faltando, como também o mesmo som que a criança emitia no balbucio continua, mas com um valor relacional diferente dentro do sistema.

Começa, então, uma certa progressão definida em termos de relações implicativas hierárquicas na ordem de aquisição de distinções opositivas, de tal maneira que as distinções fônicas (mais tarde estabelecidas em termos de traços) não-marcadas têm a tendência de aparecer antes das oposições marcadas, segundo o princípio de contraste máximo, ou mínimo consonantismo e mínimo vocalismo. Mostra também como as marcadas são mais comumente atestadas nas línguas do mundo e as não-marcadas são menos atestadas nas línguas (por exemplo, oposição no sistema de líquidas, distinção entre chiantes e sibilantes).

Conquanto reconheça a extrema variabilidade individual e cronológica, Jakobson, a título de exemplificação, mostra como as primeiras distinções vocálicas tendem a ser a oposição entre uma vogal mais aberta e uma mais fechada, dependendo, obviamente, do sistema relacional da língua em questão. Veja que isto é diferente de dizer que os sons são [a] versus [e] ou versus qualquer outro som. Assim, numa hierarquia de oposições de traços, o mais geral e superordenado tem a tendência de vir antes do mais específico e subordenado.

Assim, com as formas não-marcadas tendendo a aparecer antes de formas marcadas, os "wild sounds" do balbucio transformam-se em entidades de valor lingüístico.

O que está em jogo, então, não é a capacidade de produzir ou perceber um som particular, mas seu valor distintivo dentro de um sistema fonológico. Acrescenta, explicitamente,

"every attempt to restrict the speech sound to an external empiricism is unsuccessful".

Assim, a denominação de suas hipóteses explica-se:

Da identidade: tanto o adulto quanto a criança (quanto o afásico) relacionam-se com a/movem-se na mesma língua.

Da regressão (relativa à afasia): a progressão, na fala do afásico, seria inversa, obedecendo ao mesmo tipo de implicação relacional (ver Scarpa, 2003, a este respeito).

Da descontinuidade: diferente natureza estrutural entre os sons do balbucio e os das primeiras palavras, mesmo que alguns deles sejam, na substância, os mesmos.

É interessante notar, então, que, para Jakobson, o descontínuo - porque relacional é que vai imprimir o caráter da identidade entre a língua do adulto e a da criança. Bom também notar que seus traços distintivos, estabelecidos alguns anos depois, são vistos como universais porque atestados nas línguas e não porque são biológicos. São traços de denominação e origem corpórea, estabelecidos acústica ou auditivamente (grave/agudo; 
SCARPA - A criança e a prosódia: uma retrospectiva

compacto/difuso, etc.), porém cuja função é simbólica, distintiva, fonológica. Do orgânico ao simbólico, eis o percurso epistemológico de sua fonologia.

Sua hipótese exerceu impacto duradouro na aquisição da fonologia e na afasiologia, porém rapidamente incorporou uma perspectiva empiricista de procurar, na fala da criança, evidência em favor da "ordem de aquisição dos fonemas". Obviamente a "hipótese da regressão" foi relegada ao esquecimento até bem recentemente porque não poderia mesmo sobreviver com uma interpretação empiricista e perceptualista.

Apesar dos desvios interpretativos, com relação à Aquisição da Linguagem, na verdade, um razoável corpo de evidência em diversas línguas, de variadas tipologias, corroborou a previsão jakobsoniana de ordem de aquisição fonemática na fala de crianças adquirindo línguas indo-européias ou não.

As críticas à sua hipótese, nas décadas subseqüentes, deram-se dentro das seguintes linhas de raciocínio:

1) Uma visão perceptualista sobre o primeiro ano de vida supõe que a criança "sabe", mas não "produz" palavras ou contrastes, quer por inabilidade motora, articulatória, quer por limitações de processamento.

2) Numa corrente de raciocínio que começa com Oller (1976), nega-se a relação pessimista entre o balbucio e o sistema fonológico a partir das primeiras palavras. Trata-se de estudos que mostram a semelhança fônica existente entre os sons e a estrutura das sílabas mais freqüentes no chamado balbucio canônico (CV) e os sons mais freqüentes emitidos no período das primeiras palavras. Prevê-se, portanto, continuidade entre os "padrões silábicos" do balbucio e os sistemas fonológicos posteriores baseados numa noção de semelhança de substância.

3) Diferenças individuais. A ordem de aquisição de segmentos não é aquela proposta por Jakobson, embora, estatisticamente, a evidência seja maior a favor da progressão de oposições fonemáticas de Jakobson.

4) Diferenças translingüísticas. A ordem de aquisição de fonemas não é homogênea nas línguas, mas é dependente do sistema fonológico da língua a que a criança está exposta.

Como se vê, as críticas, na sua maioria, não se sustentam. Na melhor das hipóteses, elas se direcionam a uma parte mais periférica da proposta de Jakobson, a saber, a previsão de tendências na ordem de aquisição, mas não se referem ao ponto central: o caráter distintivo, relacional do sistema fonológico das primeiras palavras, por oposição à natureza mais errática ("à procura de sentido", segundo Jakobson) do balbucio. Resvalam, quase sempre, para uma valorização mal interpretada da substância fônica, da empiria pretensamente percebida pelo aprendiz, recusada por ele.

Outras críticas mais conseqüentes, como sensibilidade da criança às regularidades distribucionais da língua materna (Ex.: em finlandês, /d/ é tardio por ser de distribuição marginal e restrita) não derrubam o pleito de Jakobson em favor do valor relacional da unidade fônica; ao contrário, é argumento em favor dele. 
Cadernos de Estudos Lingüísticos 47(1) e (2) - Jan./Dez. 2005

Uma polêmica mais geral diz respeito ao caráter universal dos traços. A rigor, Jakobson elenca um acervo de traços acústicos, corpóreos, atestados nas línguas, a serem significados ou simbolizados por elas, as línguas. Negou, até o fim de sua vida, o caráter inato (porque biológico) que se imprimiu depois às teorias de traços distintivos.

Por que as propostas de Jakobson foram assim incompreendidas na área?

Uma pista para explicar este fato está no recente trabalho de D'Angelis (2002), que, seguindo Mattoso Câmara Jr., mostra como, nos Estados Unidos, a Fonologia começa com Sapir, independentemente de Saussure e de Praga. Não obstante, Bloomfield redireciona o raciocínio de Sapir para um empiricismo que passa a marcar o descritivismo americano. No que pese a influência de Sapir, que continuou, a reflexão fonológica toma outra direção, como mostram as palavras do "insuspeito Pike", no dizer de Wilmar:

\section{A influência de Sapir, afora a sua insistência nos sistemas fonológicos, continua com muita intensidade.}

Segundo Mattoso Câmara, Bloomfield foi quem deu "a base teórica para o desenvolvimento da 'fonêmica', a réplica americana para a 'fonologia' de Trubetzkoy". Ao recusar a insistência de Sapir na noção de sistema fonológico, a perspectiva descritivista do distribucionalismo empobrece sobremaneira a visão do componente fonológico das línguas, reduzindo-o a meros inventários de fonemas.

As críticas a Jakobson vêm precisamente desta tradição empiricista e psicometrista da Aquisição da Linguagem, que não conseguiram mesmo entender a fonologia de inspiração praguense.

\section{Dupla face, dupla vocação.}

É tentador lançar mão das reflexões de Didier-Weill (1999) sobre a pulsão invocante e aproximá-las das reflexões que tenho feito sobre a dupla face da prosódia e sobre a continuidade e descontinuidade presentes na materialidade fônica com que a criança se depara:

A vocação para tornar-se humano nos é originalmente transmitida por uma voz que não nos passa a fala sem nos passar, ao mesmo tempo, sua música: a música desta "sonata materna" é recebida pelo bebê como um canto que, de saída, transmite uma dupla vocação: está ouvindo a continuidade musical de minhas vogais e a descontinuidade significante das minhas consoantes? (Didier-Weill, 1990: )

O mundo que será dado ao bebê terá a "marca de um contínuo" e um "descontínuo". No descontínuo, ele encontrará o campo da lei que discriminará as coisas. No do contínuo, ele terá a entrada num novo mundo, que se abre para novos possíveis, que, no entanto, não será incoerente, mas guiado.

Assumindo a anterioridade do simbólico sobre o som,

"o puro som musical da voz materna é interpretado e recebido como sentido pelo ouvinte original que é o infans" (Didier-Weill, 1990, p.150). 
SCARPA - A criança e a prosódia: uma retrospectiva

Numa metáfora com a música e com a terminologia operística, Didier-Weill continua a insistir num primitivo do contínuo melódico que antecipa a segmentação, mas não cede propriamente lugar a ela, não é substituído por ela:

"Supomos que o infans, antes de ouvir o som das palavras escandidas, isto é, a dimensão do parlar cantando da mãe, ouviria previamente o sentido dos sons, isto é, a dimensão do prima la voce." (id., ibid., p. 154)

As duas dimensões, a da descontinuidade e a da continuidade, caminham juntas:

"[...] podemos supor que, quando acede à inteligibilidade da descontinuidade dos fonemas e das palavras, ele permanece, ainda assim, sob a ascendência originária da pura sonoridade materna." (id., ibid.)

E a dupla face/dupla vocação (palavra cognata de "voz") instala a permanente tensão, presente na entrada do infans na língua:

Este infans teria, assim, de encarar o fato de que a linguagem lhe seria transmitida como habitada por esta contradição interna: por um lado, é-lhe transmitida uma lei simbólica fundada na integração das escansões linguageiras, próprias para transmitir o sentido simbólico do código; por outro lado, é-lhe transmitida ao mesmo tempo uma subversão desta lei: a pura continuidade sonora produzida pela voz desta diva que é a mãe tende, com efeito, a abolir a descontinuidade que transmite a inteligibilidade do sentido. (id., ibid.)

\section{REFERÊNCIAS BIBLIOGRÁFICAS}

CAVALCANTE, M. B. (1999). Da voz à língua: a prosódia materna e o deslocamento do sujeito na fala dirigida ao bebê. Tese de doutorado inédita. IEL, Universidade Estadual de Campinas.

D’ANGELIS, W. (2002). O alinhamento pró-Estados Unidos da Fonologia no Brasil. In: IX International Conference on History of Language Sciences. São Paulo, USP; Campinas, UNICAMP, 27 a 30 de agosto de 2002.

DIDIER-WEILL, A . (1999). Invocações. Dionísio, Moisés, São Paulo e Freud. Rio de Janeiro, Companhia de Freud Editora.

GEBARA, E.M.S. (1984). The development of intonation and dialogue processes in two Brazilian children. Tese de doutorado inédita. Universidade de Londres.

JAKOBSON, R. (1941). Child language, aphasia and phonological universals. Haia, Mouton (tradução para o inglês em 1968).

DE LEMOS, C. (2002). Das vicissitudes da fala da criança e de sua investigação. Cadernos de Estudos Lingüísticos, $\mathrm{n}^{\circ}$ 42. Campinas, IEL/UNICAMP.

. (1999). A criança com(o) ponto de interrogação. In: LAMPRECHT, R. (org.). Aquisição da Linguagem. Questões e análises. Porto Alegre: EDIPUCRS.

(1992). Los procesos metafóricos y metonímicos como mecanismo de cambio. Substratum I.

LIER-DE VITTO, M.F. (1998). Os monólogos da criança: delírios da língua. São Paulo: EDUC/ FAPESP. 
OLLER, D.K. (1976). Infant vocalizations: a linguistic and speech scientific perspective. Miniseminar for the American Speech and Hearing Association, Houston.

SCARPA, E.M. (1985). Intonação e processos dialógicos: fusão ou diferenciação? In: DE LEMOS, C. T. G. (org.) Aquisição da Linguagem. Série Estudos. Faculdades Integradas de Uberaba, p. 56-74.

(2003). Prosody and language loss: a case study on prosodic difficulties in fluent aphasia.In: I PaPI, Lisboa, 11-12 de junho de 2003.

. (1999). Sons preenchedores e guardadores de lugar: relações entre fatos sintáticos e fatos prosódicos. In: SCARPA, E. M. (org). Estudos de Prosódia. Campinas: Editora da UNICAMP, p. 253-284.

. (1995). Organizações rítmicas na fala inicial. Anais do IX Encontro Nacional da ANPOLL, Universidade Federal da Paraíba, p. 1260-1266.

. (1990). Intonation and dialogue processes in early speech. In: CONTI-RAMSDEN \& SNOW, C. (orgs.). Children's Language, v. 7. Hillsdale, N.J, Lawrence Erlbaum Ltd., p. 147-169. 